\title{
ANNOTATIONS
}

\section{The In-Patient Treatment of Ophthalmia Neonatorum in London}

Readers of these columns know that in 1918 the Metropolitan Asylums Board, at the request of the Ministry of Health, established an institution, St. Margaret's Hospital, for the treatment of cases of ophthalmia neonatorum. This hospital now contains accommodation for sixty babies and treatment is available for those mothers who are willing to receive it. The accommodation provided at the hospital has seldom been fully utilized and the Metropolitan Asylums Board have also experienced a continual difficulty in securing the babies in the earliest stages of the disease. The Board therefore recently convened a widely representative conference which it was hoped might devise means to take greater advantage of the facilities provided by the hospital. This conference took place on July 19,1922, and was attended by representatives of the Board, including Dr. F. F. Caiger, Mr. M. S. Mayou, and Dr. C. Price. The Ministry of Health was represented by Dr. H. O. Stutchbury and Dr. Janet Campbell, and the London County Council by Dr. Elizabeth MacRory. The section of ophthalmology of the Royal Society of Medicine sent Sir John Parsons and Mr. J. B. Lawford. The Medical Officers of Health for St. Pancras and St. Marylebone were present. The local medical and Panel Committee for London sent two representatives, as did the Central Midwives Board and the Midwives Institute.

Mr. Mayou said that, roughly, one-third of the cases of ophthalmia neonatorum notified in London had been admitted to the Hospital and, upon an average, cases were received on the ninth day of the disease, while in other large towns they were received about the fifth day. A very serious drawback to the work was that St. Margaret's Hospital had got the name of a hospital for venereal disease, but every effort was made to avoid difficulty on this score.

We hope the conference may help to fill the beds of this Hospital. It would be interesting to know what steps the Asylums Board have taken to make the public aware of the existence of this institution. In the meantime, in spite of the expected report of the departmental committee on blindness, which may suggest other ways of dealing with these cases, it is important to make the work as widely known as possible.

\section{Out-Patient Work in Ophthalmology in New York}

The associated out-patients' clinics of New York were organised in 1912 as a federation of out-patient departments of the leading hospitals of the city, together with a number of dispensaries 